\title{
WAARDIGHEDEN OF AMBTEN IN DE TANIMBAREESCHE MAATSCHAPPIJ.
}

DOOR

P. DRABBE.

In de oude Tanimbareesche Maatschappij had men verschillende waardigheden, groote en kleine; maar groote of kleine, de dragers dier waardigheden voelden zich; ze voelden zich maberat, ze voelden zich gewichtig, en o wee diegene, die hen dorst te verlichten, zooals ze dat uitdrukten, nafmberane sir; hij moest heel wat betalen om daardoor te maken, dat de waardigheidsbekleeder weer gewichtig was, ma namin maberat nbali, en deze wist niet goed meer of hij zich ongelukkig moest voelen, omdat hij beleedigd was geworden, ofwel zich verheugen over de herstelling van de achtbaarheid welke hem ten deel zou vallen, nog wel in klinkende munt, klinkklaar goud, helwitte marmerzuilschelp, of zwaarwegend ivoor.

Laten we door een kort artikel al die hoogheid van de Tanimbareesche wereld, met ondergang bedreigd, aan de vergetelheid trachten te ontrukken. We zullen al die waardigheden noemen met de Jamdeensche namen, $\mathrm{nml}$. in de taal welke gesproken wordt op de heele Oostkust van het eiland Jamdena, het grootste eiland van de Tanimbar-groep, waar de oude adat zich het langst en het zuiverst heeft staande gehouden.

Een waardigheid of ambt noemde men bain, mv. banir; de dragers der waardigheden waren mangondi-banir, ook wel mellar. Onder de vele waardigheden waren er drie, die gront waren, voornamer dan de andere; die noemde men dan ook de groote waardigheden, bain silaiar, om ze te onderscheiden van de mindere, nml. bain anakir; zoo sprak men ook van mel'silaiar en mel'angkir.

De drie groote waardigheidsbekleeders waren de pnoewe ndoean, of kampongeigenaar; de mangafwajak, of afroeper; de mangsombe, of offeraar. 
De kampongeigenaar is diegene, welke rechtstreeks afstamt en stamhouder is van hem, die volgens de overlevering het eerst de plaats bewoonde, waar de kampong gebouwd werd, of m.a.w. den kampong stichtte. Door kampong moet men verstaan alleen de plaats waar men samenwoont, dus niet alle gronden, die eigendom zijn ofwel van de kamponggemeenschap, ofwel van eenlingen, welke eenlingen dan grondeigenaars genoemd worden, ambat-ndoenir. In een kampong kunnen dus veel grondeigenaars zijn, maar ook verschillende kampongeigenaars, bijv. twee of drie, daar het kan gebeuren, dat twee of drie menschen samen vroeger de plaats in bezit namen.

De kampongeigenaar heeft de macht, iemand het recht toe te staan, zijn huis te bouwen in den kampong, en daardoor tegelijk het recht om van de gemeenschappelijke gronden en goederen gebruik te maken. Hij heeft echter niet de macht, om het eens gegeven recht weer af te nemen.

Verder is het aan hem, om bij kwestie van algemeene verhuizing te beslissen, of men werkelijk verhuizen zal of niet. Hij neemt echter geen beslissing, zonder eerst de gemeenschap te hebben gehoord, en haar goedkeuring te hebben verkregen.

De kampongeigenaar werd ook wel genoemd ririboen réréngjar, welke uitdrukking beteekent: de britsen van een groote gemeenschappelijke feest- of strijdprauw. Ik spreek van feest- of strijdprauw, want feesten en strijden, dans en perkara waren bij den echten Tanimbarees zooveel als synoniem; de groote vlerkprauw met den met snijwerk versierden voorsteven wekt aanstonds zelfs bij jonge Tanimbareesjes, die het echte oude feest- en strijdleventje, het oude pronken en vechten niet meer meegemaakt hebben, aanstonds het idee van kampongroem. Daarvandaan dan ook, dat de kamponggemeenschap vaak de sori genoemd wordt; sori is het algemeene woord voor prauw, en het dorpsplein, de dansplaats, waar ook alle groote zaken werden behandeld, was vaak gebouwd in den vorm van een sori. Een van de voornaamste onderdeelen van zulk een groote feestprauw waren de britsen, vier in getal, waarop men zich even senang voelde, zooals men dat nu nog wel hoort zeggen, als op den vloer van een flink Tanimbareesch huis; daar konden ze eten en slapen, evengoed als in hunne huizen; daar zaten gedurende de reis de groote waardigheidsbekleeders, die geen hand mochten uitsteken naar roeispanen of boomstokken; vandaar, dat de pnoewve ndoean, de kampongeigenaar, ook betiteld werd met den naam van 
die britsen; ririboen beduidt de britsen op iedere vlerkprauw, en réréngjar, dat snijwerk beteekent, duidt er op, dat men spreekt niet over zoo maar de een of andere vlerkprauw, maar alleen over de groote feest- en strijdprauw, want men vergelijkt natuurlijk de gemeenschap niet met een gewoon prauwtje; een kampong op Tanimbar, hoe klein ook, was in de oogen van zijn bewoners nooit een hulkje op de woeste baren, dat hulpeloos daar heendobberde, maar een zeekasteel, dat voor niets bang hoefde te zijn. Vandaar dan ook, dat men in later dagen zoo graag zijn kampong vergelijkt met een groot uitheensch schip, en hem kabal noemt, als men plechtig wil zijn, en plechtig willen zijn is ook een van de eigenschappen van den echten Tanimbarees, en een van de middelen om plechtig te zijn is beeldspraak.

Om verder te gaan, waarschijnlijk is de kampongeigenaar oorspronkelijk per se de afroeper of Mangafwajak, en als er meer kampongeigenaren waren, werd door gemeenschappelijk goedvinden één hunner beschouwd als de afroeper.

Het gebeurde ook wel, dat de kampongeigenaar aan een ander in den kampong het recht afstond van afroeper te zijn, maar in dat geval moest een beslissing door den afroeper genomen toch nog goedgekeurd worden door den kampongeigenaar.

Waar, wat ook gebeurt, geen kampongeigenaar is, moet de afroeper zijn: waardigheid ontvangen hebben door een besluit van de gemeenschap.

De stamhouder van den eersten afroeper is over het algemeen de tegenwoordige afroeper. Loch het gebeurde ook wel, dat door een besluit van de gemeenschap, of van de gemeenschap samen met den kampongeigenaar, de waardigheid van afroeper werd overgebracht naar het huis van een ander. Dit echter zou niet gemakkelijk gebeuren, daar men het eenmaal verworven recht aanziet als iets heiligs, wat niet straffeloos zonder heel goede redenen vervreemd kan worden. Het onrechtvaardig vervreemden van dergelijke rechten heeft volgens Tanimbareesche opvattingen zeer vaak kwaadaardige ziekten en vroegen dood ten gevolge.

De waatdigheid van afroeper is het, die het meest overeenkomt met de tegenwoordige door de Regeering ingevoerde waardigheid van orang kaja, en in het begin is door de eerste Posthouders en Gezaghebbers dan ook meestal de waardigheid van orang kaja gegeven aan de afroepers, ten gevolge van hun overleg met de bevolking, die meestal als hun grooten man den afroeper aanwezen. 
De afroeper was in tegenstelling met den offeraar de vader van den kampong, pnoezue dalam amnir. De offeraar was de moeder, pnoewe dalam ennir. De afroeper was de groote man in alle gemeenschappelijke aangelegenheden, hoewel de offeraar bijna even hoog stond als hij. De grootste gemeenschappelijke zaken of aangelegenheden waren de oorlogen met alles wat er bij behoorde, het sluiten van vriendschap met andere kampongs, en het ruilen van kostbaarheden met dezelve. Nemen we als voorbeeld de oorlogen. Als er kwestie was van oorlogvoeren met een anderen kampong, dan werd door den afroeper de gemeenschap bij elkaar geroepen, en door hem werd na gemeenschappelijk overleg en na algemeen goedvinden uitgemaakt, of er oorlog zou zijn, ja of neen. Hieruit blijkt wel, dat hij niet veel meer was dan een primus inter pares. Daarbij komt, dat ook nog een Godsoordeel werd gevraagd. De offeraar offerde een hen aan het Opperwezen, en dan werd uit den a.derloop in het hart van het offerdier gelezen, of de strijt1 met succes zo11 bekroond worden of niet. Gaf het Opperwezen door een bepaalde ligging der hartaderen te kennen, dat men succes zon1 hebben, dan viel pas de definitieve beslissing, dat mer den strijd zou wagen. Soms echter ging men ten strijde nietteợenstaancle de aanwijzing Gods weinig succes of zelfs tegenslag te verwachten gaf.

Als men in den strijd eenige koppen had bemachtigd, dan werden die plechtig aan vader en moeder gebracht, die ook de kostbaarheden in ontvangst namen, welke waren geroofd en als buit meegebracht, welke kostbaarheden niet hun persoonlijk bezit werden, maar door hen als gemeenschapsgoederen werden bewaard. Vandaar, dat men ook het huis van den afroeper wel de kmberre noemde, d.w.z. de vliering of zolder; op de vlieringkjes in de Tanimbareesche huizen worden nml. meestal de kostbaarheden bewaard.

Als eenmaal de oorlog was begonnen, en zoo lang hij duurde, moest de offeraar in zijn huis blijven, en dat verblijf in zijn huis werd offeren genoemd: nsombe. Hij moest den zegen van boven afsmeeken over de wapens van zijn kamponggenooten.

In tegenstelling met het voorgaande kon het ook wel gebeuren, dat vader en moeder absoluut niets van een oorlog wilden weten, doch de kinderen er maar toe overgingen. Het waren dan de jongelui, tabwerjar, die er en corps toe besloten. Maar ook in dat geval werden de gesnelde koppen enz. hun eerbiedig aangeboden, en door hen ook meestal zonder veel tegenstribbelen aangenomen.

Zooals in oorlogskwesties ging het ook in andere gemeenschap- 
pelijke zaken: de vader en moeder waren theoretisch de baas, maar ze beslisten niets zonder goedvinden van de gemeenschap, en vaak werd door de gemeenschap tegen hun oordeel ingegaan.

Een andere kwestie is, of de afroeper in partikuliere zaken ook eenige macht had. Hierop meen ik te moeten antwoorden van neen. Men bracht nooit een partikulier geschil voor den afroeper, om door hem beslist te worden. Wel gebeurde het, dat bij een geschil, waarbij men bijna handgemeen werd, de afroeper of de offeraar, of beiden tegelijk tusschen beide kwamen, en de zaak trachtten te sussen, en dan luidde ook het algemeen oordeel: onze waardigheidsbekieeders (mellar) komen tusschen beide, houdt dus op; luistert naar hen want het zijn onze adellijken. Vaak hield de ruzie dan uit eerbied voor de hooge oome's op, maar vaak konden zij er niets aandoen; en als men hen weerstond, en er werden klappen uitgedeeld, of er vielen dooden, dan volgde daarop geen straf of boete.

Toch bestonden boete's. Boete eischen noemde men rtak toeak, boete betalen rosse toeak, letterlijk sagero vragen, en sagero doen; tocak beteekent sagero, maar het wordt figuurlijk vaak gezegd van te betalen geld of te betalen kostbaarheden. Er bestonden zelfs zware boete's, waarmee vergeleken die van ons wetboek kinderspel zijn. Maar die konden alleen opgelegd worden door de gemeenschap en krachtens een gemeenschappelijke afspraak. Als er bijv. eens te veel getwist werd in een kampong, dan kwam men op een goeden dag, onder den indruk van een pas voorgevallen vechtpartij, bijeen, en men sprak af, niet meer te twisten, en wie tegen die afspraak zou ingaan, zou één of twee varkens, een olifantstand, of andere kostbaarheden aan de gemeenschap moeten betalen. Eén riep er dan: als je het allemaal goedvindt, heft dan een hoera-geschreeuw aan (mpjoroe). Er werd een driedubbel hoera geroepen, en de zaak was klaar, de bepaling was wet geworden. De eventueele overtreder moest betalen, en zoo hij niet wilde, werd hij gedwongen, zijn varken werd gepijld, of de kostbaarheden werden hem afgenomen, iets wat vaak ook weer tot vechtpartijen, zelfs met doodelijken afloop aanleiding gaf.

De genoemde boete was een werkelijke gemeenschapszaak; men had ook nog andere boete's, nml. die der jongelui, tabwérjar; de tabwérjar waren als een staat in den staat, en wat hun belangen betrof waren ze almachtig, legden boete's op, maakten wetten naar gelang het hun goeddacht, maar altijd gemeenschappelijk. Zoo sprak men soms af, dat men een groote vasten zou houden, rosse bowase, 
ofwel, dat men een algemeen dieet zou voorschrijven, rosse siri-siri, met het doel zich leniger en slanker te maken, iets wat geheel in de lijn lag van de jongelingschap, die aan niets anders dacht dan aan het opsieren van het lichaam, en aan pronken zonder eind: men heeft de tabwérjar wel de dandy's der Molukken genoemd en met recht. Iemand die de bepalingen van de jongelingschap niet nakwam, bijv. de vastgestelde vasten niet hield, of op de vastgestelde uren van den dag niet aanwezig was om te pronken in het publiek, rlambjor, of er niet om gaf een bepaalde versiering op een bepaalden tijd te dragen, of die zich dit of dat niet wilde aanschaffen, wat de jongelingschap als mode had aangewezen, hij kreeg een boete even goed als degene, die zooals we boven zeiden een gewichtig besluit van de heele gemeenschap goedgekeurd door vader en moeder, had overtreden.

Men ziet, dat in de Tanimbareesche maatschappij zeer democratische opvattingen golden. Al werd er niet met democratie gedweept en al werd er zelfs niet over geredeneerd of gefilosofeerd, practisch was de volkswil de baas. Daarvandaan ook, dat men geen hormatsbetuigingen kende, zooals die bij andere volkeren voorkomen, en de waardigheidsbekleeders waren even gewone landbouwers, jagers en visschers als al de andere leden van de gemeenschap.

Het karakter van den Tanimbarees vertoont fierheid en openheid, welke vaak tot trotschheid en brutaalheid overslaan. Daaraan hebben misschien voor een groot deel hun democratische gewoonten haar ontstaan te danken, en van den anderen kant is het ook wel waarschijnlijk, dat de democratie in hun maatschappij die trekken van hun karakter nog heeft versterkt.

Men denke nu echter niet dat elk individu geheel in de gemeenschap opging, en alle persoonlijkheid verloren liep. Dat is waar voor de zwakkeren; zwakkeren van aanleg en karakter, zwakkeren wegens hun gebrek aan familie, m.a.w. gebrek aan voldoende bescherming tegenover den wil van de gemeenschap. Menschen die wat flink van karakter waren, er: bovendien zich omringd wisten door een talrijke familie, broers of zwagers, brachten het soms wel zoover, dat de gemeenschap voor hen moest zwichten. Wat betreft particuliere zaken, waaronder vooral hartazaken een zeer voorname plaats innamen, wisten zulke lui de tegenpartij geheel naar hun wil te dwingen, èn wat betaling èn wat het aannemen van een betaalde betaling aangaat, maar ook de gemeenschap stond soms machteloos tegenover hen, en men had tegenover sommige lieden den moed niet 
een opgelegde boete werkelijk te eischen of af te dwingen. Zoo ook hadden de groote waardigheidsbekleeders meer of minder practische macht naargelang zij schranderder, brutaler en meer door een groote familie gerugsteund waren.

Zoo had men ook de zoogenaamde kleinere waardigheden, bain angkir. Ze hadden eigenlijk weinig macht, maar als ze een grooten mond hadden, een vlugge greep naar pijl en boog, en bovendien veel familieaanhang, hadden ze practisch soms veel invloed, en enkele keeren meer dan een hooger machthebber, die echter wat bedeesd was uitgevallen, wat vredelievender was, niet gauw naar de wapens greep, of wiens familie zich niet erg had uitgebreid.

De voornaamste der mindere waardigheidsbekleeders waren de mangatanoek, spreker, en de sori-loeri, voorganger. $\mathrm{Zij}$ hadden evenals de mel'silaiar op de natar, het dorpsplein, hun aangewezen plaats, een groote platte steen, totobat. De sori-loeri, letterlijk de voorsteven, zat op het voorste deel van de natar, die, zooals we boven zeiden, dikwijls den vorm had van een boot, of tenminste altijd beschouwd werd als een boot. Wat verderop zaten vanaf den sori-loori gezien links de kampongeigenaar, en rechts de offeraar; aan het anciere uiteinde zaten links de afroeper, en rechts de spreker.

De spreker was degene die altijd en overal, dus zoowel in den kampong als in den vreemde. het woord moest voeren in naam en in opdracht van mangafrajak en mangsombe; dezen lieten hem de onderhavige zaak uiteenzetten, lieten hem redetwisten enz. enz., maar als hij niet sprak naar hun zin, niet duidelijk genoeg, niet flink genoeg of iets dergelijks, dan vielen ze hem in de rede, verbeterden hem enz. Hij en de sori-loeri vooral konden heel wat invloed en practische macht hebben, als ze voldeden aan de eischen, die daarvoor gesteld werden in de Tanimbareesche maatschappij, zooals we boven reeds zeiden, een goede dosis onbeschaamdheid, wat opvliegendheid en een flinke familie.

De sori-locri werd ook wel genoemd de snjomb'loeri, d.w.z. het begin van het offerfeest; ook nog de mangbaloean, d.w.z. degene die vooropgaat; verder de mangkei, sleeper, of mangkei loeri, de voorsleeper; ook sprak men nog van manglair, wat ook zoo veel beteekent als voorganger. Hij was altijd het begin van elke perkara en van elke plechtigheid. Alvorens te beginnen met een of andere gewichtige zaak, ging men in zijn huis een klein offertje of liever een pruim offeren aan het Opperwezen en de voorouders, snjaw'- 
falondi, een pruim om de zaak te richten. Als men verhuisde naar een andere plaats, moest hij het eerst zijn huis opzetten, alvorens een ander aan het zijne mocht beginnen. Bij een openbaar feest gaf hij de eerste slag op de trom. Als men gemeenschappelijke tuinen maakte, werd eerst zijn rijst geplant, en bij het oogsten moest iedereen wachten met het oogsten, totdat men de rijst van den sori-loeri binnen had, enz. enz.

Ook bij niet van de gemeenschap uitgaande jacht- of tuinfeesten sprak men van sori-locri; dat waren echter partikuliere sori-loeri's, die maar voor de gelegenheid door de belanghebbenden werden aangewezen, al naar de omstandigheden; men gebruikte daarvoor dezelfde benamingen, als die welke we boven gaven voor den soriloeri der gemeenschap. Het was echter geen waardigheid, en had met de gemeenschap niets uit te staan.

In aansluiting híermee kunnen we even spreken over den mangmbelat, degene die de zaak afsiuit. Dit was heelemaal geen waardigheid, maar bij iedere minder voorname zaak, zooals jacht, landbouw enz. stelde men een mangmbclat aan, die de laatste plaats innam, wiens rijst het laatst geplant en het laatst geoogst werd, enz. Ook bij niet van de geheele gemeenschap uitgaande jacht en tuinbouw sprak men zoowel van mangmbclat als van sori-locri, en al was het geen waardigheid, ieder was toch wel graag mangmbelat, want dan was hij iets anders dan de groote massa, en voelde hij zich min of meer buiten en boven het gros staan. Opmerkelijk is, dat in het Fordaatsch ons aanstellen wordt vertaald door nsidoek, d.w.z. afscheiden.

Een andere kleinere waardigheid is de mangfaloeroek, d.i. een soort offeraar; hij offert in groote zaken meer om de voorbereiding ervan, de besprekingen enz. aan het Opperwezen en de dooden aan te bevelen. Het eigenlijke of fer is de zaak van den mangsombe, maar het of feren, dat bestaat in pruimen aanbieden aan dooden en Opperwezen, is zijn ambt. Hij is een echte, hoewel mindere, waardigheidsbekleeder bij de gemeenschap, en zijn waardigheid is als al de andere erfelijk. Men hoort echter den naam van mangfaloeroek ook wel geven aan dengene, die bij een meer partikulier feest, een door partikulieren georganiseerde jachtpartij enz. de noodige of fers brengt.

De mangos'wate is, of liever zijn degenen, die als ambt hebben bij gemeenschappelijke of fermaaltijden het eten in parten te verdeelen. In iederen kampong heeft men er twee.

Verder heeft men nog twee waardigheden, die zuiver waardigheden zijn, waaraan geen enkele functie is verbonden, $\mathrm{hml}$. de 
mangkit'krawe, en de mangkait wilin. Hier zijn we weer volop in de beeldspraak. Mangkit'krawe beteekent hoozer; mangkait wilin beteekent stuurman. Oorspronkelijk zal wel aan de waardigheid een functie beantwoord hebben, maar bij het nog levend geslacht is daarvan geen spoor meer te bekennen.

Ten slotte heeft men nog twee waardigheden, die ongelukken van den kampong hebben af te weren, nml. de mangjebas bati, de steenengooier, en de mangfanak boeke, de haarschieter. Met de letterlijke vertaling heb ik die namen echter nog niet veel duidelijker gemaakt. Als er een epidemie heerschte, of in den laatsten tijd veel dooden waren geweest, moest de mangjebas bati, op bevel van vader en moeder, bij zonsondergang de zon een steen achternawerpen, weike steen de ziekte verbeeldde, die zooveel menschen deed sterven. Tellend tot negen wierp hij bij negen den steen de zon achterna, njebas bati nlarat lere. In de Noordelijke dorpen van de Oostkust thad men den mangkei babi, die door een varken negen maal rond den kampong te sleuren en dan weg te negenen, de epidemische ziekte over den kampong-ringmuur deed verdwijnen.

De mangfanak babi verstond de kunst om de kwade gevolgen van een snelpartij weg te negenen en zelfs op den vijand, waar men gesneld had, over te negenen. Hij nam enkele haren van de gesnelden, bevestigde die aan een pijlschacht, en schoot deze over den kampongmuur de wijde wereld in, na eerst tot negen geteld te hebben, nfanak kalin maberat ma ntait lan kitnin kande, hij schoot de zwaarte weg opdat ze alleen zou wegen op den vijand.

Nog moeten we even spreken over vier functies, die eigenlijk aparte waardigheden zouden kunnen zijn, maar uitgeoefend worden door een van de bovengenoemde waardigheidsbekleeders. Men spreekt $\mathrm{nml}$. van mangsindak, mangbise-sife, mangndirin en mangraoes. Mangsindak beteekent: degene die de klapper opensplijt, en men bedoelt daarmee degene die, alvorens de gemeenschap op jacht of vischvangst ging, uit een gehalveerden klapper een Godsoordeel vroeg over den te verwachten uitslag. Het werd gedaan door den sori-loeri.

Mangbise-sife beteekent de opensnijder van de kip, en men bedoelt daarmee dengene, die, alvorens de gemeenschap besloot tot oorlog of tot een andere gewichtige zaak, uit het hart van een kip aan het Opperwezen een aanduiding vroeg omtrent het tijdige of ontijdige van den te ondernemen oorlog enz. Deze functie kwam toe aan mangafwajak en mangsombe samen. 
Mangndirin is de verkoeler, d.w.z., hij moest de gemeenschap verkoelen, als men merkte dat men in heete omstandigheden verkeerde. Een heete omstandigheid had men bijvoorbeeld, als men door een epidemie veel menschen uit het leven zag weggerukt, of als men maar geen succes had in een oorlog of in andere gemeenschapszaken. De afroeper en de of feraar raspten een klapper, wrongen het vleesch uit en de offeraar, mangsombe, ging dan het verkregen vocht, de santan, uitsprenkelen over de menigte die zich op het dorpsplein verzameld had : dit was het verkoelen, $n$-ndirin, of ook wel $n$ fandirin.

Mangraoes beteekent de slager, maar dit zelfstandige naamwoord dan genomen als afleiding van slaan en niet van slachten. Als men voor een gemeenschaps-jachtpartij zich verzameld had op de afgesproken verzamelplaats in het bosch, de matoran ain, daar de noodige offers had gebracht en de noodige onheilen had weggenomen, nam de mangatanoek een groene tak, sloeg er negen maal mede op den grond, en de negende slag werd beschouwd als signaal tot vertrek, of tot begin van de jacht, nal boeboetwar sa na nraoes ombak, sa, doe, tél, fat, lim, ném, it, wal,...... sizw, rpote sir ma rsoir lo, hij neemt een groene tak waarmee hij op den grond slaat, een, twee, drie, vier, vijf, zes, zeven, acht ...... negen, men staat op en begint de jacht.

Zooals ik boven zeide, heb ik hier de benamingen weergegeven in de taal van Jamdena's Oostkust, die we het Jamdeensch noemen; het dialect dat we volgen is het Zuiderdialect, en meer speciaal zooals het gesproken wordt in den kampong Laoeran. Ook de zaak zelf is voorgesteld, zooals men het te Laoeran opvatte, want zooals de taal van dorp tot dorp eenigszins verschilt, zoo ook de adat. Het boven beschrevene vindt men dus niet tot in de kleinste bijzonderheden aldus terug in alle dorpen op Tanimbar, maar wel in groote lijnen. Als curiositeit vermeld ik hier in een lijstje nog de namen van hen wier families in het genoemde dorp de verschillende waardigheden van oudsher bekleeden. Men heeft dan tegelijkertijd een overzicht van de besproken pankat's.

Pnoewe ndocan, kampongeigenaar:

Mangafwajak, afroeper:

Mangsombe, offeraar:

Sori-loeri, voorganger:

Mangatanoek, spreker:

Mangfaloeroek, kleine offeraar:
Waiseran.

Falaksoroe.

Kastean.

Kabine.

Sairlel.

Kabine. 
WAARDIGHEDEN OF AMBTEN IN DE TANIMBAREESCHE MAATSCHAPPIJ. 191

De familie van Kabine had zooals men ziet twee waardigheden tegelijk.

$\begin{array}{lll}\text { Mangos'wate, } & \text { verdeeler van den offermaaltijd: } & \begin{array}{l}\text { Akoke. } \\ \text { Sambonoe. }\end{array} \\ \text { Mangkit'krawe, } & \text { hoozer: } & \text { Eling. } \\ \text { Mangkait wilin, } & \text { stuurman: } & \text { Oebanaman } \\ \text { Mangjebas bati, } & \text { steenwerper: } & \text { Liboeraman. } \\ \text { Mangfanak boeke, } & \text { haarschieter: } & \text { Sainlet }\end{array}$

Saumlakki, 3 Augustus 1926. 